\section{Enrique Fanta Nuñez}

ENRIQUE LAVAL R.

Según lo relata el doctor Sixto Gerardo González, médico pediatra argentino, becado los años 1963 y 1964, en la Cátedra del Profesor Julio Meneghello del Hospital de Niños Manuel Arriarán: "las actividades docentes, asistenciales y de investigación tenían un ritmo y una intensidad que invitaban al trabajo intelectual. Se lo sentía en el ambiente, se respiraba en la fragancia de las flores y en el arrullo de los trinos de los pájaros, en los jardines del viejo hospital". En esa época el doctor Enrique Fanta se encontraba "dirigiendo el Servicio de Infectología de aquel establecimiento, donde había un número importante de meningitis, realizándose punciones lumbares y ventriculares diarias, neumopatías post-sarampionosas y estafilocóccicas". Agrega Sixto Gerardo González: "el Profesor Enrique Fanta, maestro de varias generaciones de médicos chilenos y latinoamericanos, exigente en el cumplimiento del deber y en la humanizada atención de los niños, pero primero consigo mismo y eso era un ejemplo a imitar. Es un reconocido infectólogo de nivel internacional, un verdadero médico humanista, generoso, amigo y nuestro maestro" 1 .

En el XX Congreso Chileno de Infectología, efectuado en La Serena, entre los días 5 y 8 de noviembre de 2003, el doctor Fanta fue designado Miembro Honorario de la Sociedad Chilena de Infectología, de la cual es Socio Fundador ${ }^{2}$.

Había nacido este ilustre médico pediatra el 7 de junio de 1925, realizando sus estudios secundarios en el Instituto Nacional y después los de Medicina en la Universidad de Chile, donde obtuvo el título de médico el año 1950, con su tesis sobre "Tratamiento biológico del quiste hidatídico". Entre 1946 y 1951, se desempeñó como ayudante ad-honorem de la Cátedra de Parasitología de la Escuela de Medicina de la Universidad de Chile. Con posterioridad (1951-1953), ayudante ad-honorem de la Cátedra de Pediatría de los Profesores Arturo Baeza G. y Julio Meneghello R., continuando paralelamente como docente en Parasitología, tanto en la Universidad de Chile como en la Universidad Católica, donde fue Jefe de Trabajos Prácticos entre 1955 y 1956. En 1953 ingresó a la Sociedad Chilena de Pediatría y recibió el Premio Excelencia Académica de la misma Sociedad en 1957.

Como integrante de la Cátedra de Pediatría del Profesor Meneghello, su carrera docente y asistencial la continúa en el Hospital Roberto del Río, siendo designado Profesor Encargado de Curso, luego Profesor Auxiliar, alcanzando en 1973 el nivel académico de Profesor Titular. A partir de 1968, como Profesor Agregado de la Cátedra de Pediatría de la Escuela de Medicina de la Universidad Católica, inicia la docencia de la especialidad en dicho centro de estudios médicos, recibiendo la titularidad académica en 1986. En 1990, se hace cargo de la Dirección del Departamento de Pediatría y un año después se le nombra Profesor Titular de Parasitología de dicha Universidad.

La Universidad de Génova lo recibe en 1959, efectuando una estadía en la Clínica Pediátrica G. Gaslini. Ahí, entre otros, asiste al Curso de Enfermedades Infecciosas del Prof. Paolo Tolentino. Durante el semestre académico de invierno (19591960), realiza estadía en la Clínica Pediátrica

Ex Director del Hospital de Enfermedades Infecciosas. Santiago de Chile.

Recibido: 1 septiembre 2005

Aceptado: 8 septiembre 2005 
Heidelberg, participando en varios cursos de Pediatría y Puericultura, Diagnóstico Diferencial en Pediatría y de Radiología Infantil.

Son numerosos los cursos (35 como Profesor Invitado en Latinoamérica), seminarios, mesas redondas, así como las asesorías en que ha colaborado: curso intensivo sobre Pediatría en Consultorio Externo, Choluteca, Honduras; Manifestaciones Cutáneas en las Infecciones Sistémicas (Curso de Post-grado en Dermatología); Curso Internacional de Infectología Pediátrica, Trujillo, Perú. Universidad Nacional de Trujillo, etc ${ }^{3,4}$.

Su presencia activa, siempre sobresaliente, en numerosas Jornadas Nacionales de Pediatría, sobre todo en Mesas sobre Enfermedades Infecciosas y Parasitarias. Ha dirigido varias tesis y trabajos de seminario para optar al título de médico-cirujano, profesorado en Alimentación y Educación para el Hogar, especialistas en Pediatría, Enfermería, etc.

En sus casi cien publicaciones en revistas médicas, destacan artículos sobre enfermedades infecciosas y parasitarias, tanto de clínica como de terapéutica. Cabe destacar su participación como co-autor en el Comité de Redacción del libro de Pediatría, cuyo editor jefe es el profesor Meneghello, como también en el de Parasitología de los doctores Antonio Atías y Amador Neghme. Es autor del Manual de Atención Primaria de Pediatría y co-autor del libro Pediatría Práctica en Diálogos (2001).

Miembro del Comité de Publicaciones de la Asociación Latinoamericana de Pediatría (ALAPE) y del Comité de Residencias de ALAPE; además del Panel de expertos en enfermedades infecciosas de la infancia y la niñez de la Asociación Internacional de Pediatría, como así mismo de la Sociedad Internacional de Hidatidología, etc.

Se le ha distinguido como Miembro Honorario de varias sociedades extranjeras de Pediatría (Ar- gentina, Bolivia, Ecuador, Paraguay, Uruguay, etc).

En realidad, sería muy largo y difícil detallar toda la fecunda e importante labor que ha desarrollado el Prof. Enrique Fanta, durante su vida profesional. Estoy conciente de que sólo he mencionado una mínima parte.

Enrique Fanta jubiló como Profesor Titular de Pediatría en la Universidad de Chile, en 1980, pero su actividad docente la mantiene hasta hoy, con el mismo entusiasmo de siempre, en la Facultad de Medicina de la Universidad Católica y allí el 20 de mayo de 1995, recibió la distinción de Profesor Emérito ${ }^{4}$.

Finalmente, quiero transcribir algo de lo que manifestó el doctor Miguel O'Ryan G., al presentar al doctor Enrique Fanta a la nominación de Miembro Honorario de la Sociedad Chilena de Infectología: "Enrique Fanta es un eterno buscador de la verdad y por eso es hoy tan joven como hace treinta o cuarenta años, quienes lo escuchamos opinar ayer en una sesión científica o compartimos con él en una carrera o partido de voley ball, reconociendo a un maestro que ha aprendido la humildad y sabiduría que da la vida después de muchos años vividos. Por eso Enrique Fanta es un verdadero maestro, un ejemplo de vida"2.

\section{Referencias}

1.- González G S. Meneghello, su equipo y su obra. p. 44, 59-63. Imprenta Graphic. Córdoba. Rep. Argentina. 2003.

2.- O’Ryan G M. Enrique Fanta, nuevo Miembro Honorario de la Sociedad Chilena de Infectología. Rev Chil Infect 2003; 20: 291-2.

3.- Vargas C N. Historia de la Pediatría Chilena. Crónica de una alegría. P.204-205. Ed. Universitaria. Stgo. Chile. 2002 .

4.- Fanta N E. Curriculum vitae. 